\title{
Practical Design of Digital Filters Using the Pascal Matrix
}

\author{
B. Psenicka ${ }^{1}$, F. García-Ugalde ${ }^{2}$ and V.F. Ruiz ${ }^{3}$ \\ ${ }^{1}$ Department of Telecommunications, \\ ${ }^{2}$ Department of Digital Signal Processing, Facultad de Ingeniería, UNAM and \\ ${ }^{3}$ Department of Cybernetics, The University of Reading, Reading RG6 6AY, UK. \\ E-mails: pseboh@servidor.unam.mx,fgarciau@servidor.unam.mx,v.f.ruiz@reading.ac.uk
}

(Recibido: julio de 2006; aceptado: abril de 2007)

\begin{abstract}
In the con text of the design of dig ital fil ters many re search has been done to fa cili tate their com pu ta tion. The Pascal ma trix re cently de fined in (Biolkova and Biolek, 1999) has proved its util ity in this field. In this pa per we sum ma rize the di rect trans form from the lowpass con tin u ous-time trans fer func tion $H(s)$ to the discrete-time $H(z)$ of the fol low ing main tree types of dig ital fil ters: lowpass, highpass and bandpass. Anal terna tive rep resen ta tion of the orig inal bandpass Pascal ma trix is de vel oped in this pa per that per mits to con vert sys tem at ically the lowpass continuous-time pro to type to the dis crete-time bandpass trans fer function. Wealso con sider the in verse trans for ma tion from the dis crete-time do main to the con tin $u$ ous one and we show that the in verse trans for ma tion is eas ily ob tained as the de termi nant of the sys tem need not to be com puted. Sev eral nu mer ical ex am ples il lustrate the practical utiliza tion of this tech nique.
\end{abstract}

Keywords:Filterdesign,s-ztransformation, Pascalmatrix, digitalfilterdesigntools.

\section{Resumen}

En el contexto del diseño de filtros digitales se ha desarrollado mucha investigación para facilitar su cálculo. La matriz de Pascal definida recientemente (Biolkova and Biolek, 1999) ha probado su utilidad en este campo. En este artículo se hace una síntesis de la transformación directa a partir de la función de transferencia pasa-bajas en tiempo continuo $\mathrm{H}(\mathrm{s})$ para obtener la de tiempo discreto $\mathrm{H}(\mathrm{z})$ de cada uno de los tres tipos principales de filtros digitales: pasa-bajas, pasa-altas y pasa-banda. También se desarrolla una representación alternativa de la matriz de Pascal pasa-banda original, que permite la conversión sistemática de un prototipo pasa-bajas en tiempo continuo a la función de transferencia pasa-banda en tiempo discreto. Adicionalmente se considera la transformación inversa a partir del dominio de tiempo discreto, al de tiempo continuo y se demuestra que esta transformación inversa es fácil de calcular, dado que no es necesario obtener el determinante del sistema. Varios ejemplos numéricos ilustran la utilización práctica de esta técnica.

Descriptores: Diseño de filtros, transformaciones s-z, matriz de Pascal, herramientas para el diseño de filtros digitales. 


\section{Introduction}

A large number of procedures are available for designing digital filters (Parks and Burrus, 1987); (Antoniou, 1993). Many of them transform a given analog filter into an equivalent digital filter. The digital filter design process begins with the synthesis or specification of the filter transfer function. A signal $x(t)$ presented to a filter characterized by its impulse response $h(t)$ produces an output $y(t)$ given by the convolution $y(t)=x(t)$ ${ }^{*} h(t)$ or, if using the continuous-time transforms of the signals, by $Y(s)=X(s) H(s)$. Then the continuous-time circuit of a filter is completely described by the transfer function:

$$
H(s)=\frac{A_{0}+A_{1} s+A_{2} s^{2}+\ldots+A_{m} s^{m}}{B_{0}+B_{1} s+B_{2} s^{2}+\ldots+B_{m} s^{m}}
$$

From this equation the vectors $\bar{A}$ and $\bar{B}$ representing respectively the coefficients of the numerator and denominator can be defined as:

$$
\begin{aligned}
& \bar{A}=\left(A_{0}, A_{1}, A_{2}, \ldots, A_{m}\right) \\
& \bar{B}=\left(B_{0}, B_{1}, B_{2}, \ldots, B_{m}\right)
\end{aligned}
$$

where, $A_{i}$ and $B_{i}$ are real coefficients.

In the discrete-time domain the $z$ transforms of the signals are used, and a digital filter is characterized by the transfer function:

$$
H(z)=\frac{a_{0}+a_{1} z^{-1}+a_{2} z^{-2}+\ldots+a_{n} z^{-n}}{b_{0}+b_{1} z^{-1}+b_{2} z^{-2}+\ldots+b_{n} z^{-n}}
$$

With real coefficients $a_{i}$ and $b_{i}$.

The problem of the systematic conversion from the continuous-time prototype transfer function $H(s)$ to its discrete-time version $H(z)$ is addressed in this paper considering three types of conversions: lowpass-to-lowpass, lowpass-to-highpass and lowpass-to-bandpass. The original Pascal matrix (Biolkova and Biolek, 1999) is used to achieve this systematization, and an alternative representation of the original Pascal matrix is developed in this paper to rich the lowpass-to-bandpass conversion.

The remainder of this paper is organized as follows. Section II describes the lowpassto-lowpass conversion. Section III adapts the previous development to the lowpass-tohighpass case. Section IV main contribution of this paper, develops an alternative representation of the original bandpass Pascal matrix which allows the lowpass-to-bandpass conversion. Section $\mathrm{V}$ presents the inverse conversion from the discrete-time domain to the continuous-time. In Section VI we give examples to illustrate all the cases.

\section{Lowpass-to-lowpass Transformation}

For lowpass filters the digital transfer function $H(z)$ can be obtained from the continuous-time prototype (1) using the bilinear s-z transformation (Parks and Burrus, 1987):

$$
s=c \frac{z-1}{z+1}
$$

where

$$
c=\cot \frac{\pi f_{1}}{f_{s}}
$$

and the constants $f_{1}$ and $f_{s}$ represent the lowpass corner and sampling frequencies, respectively.

From the transfer function (3), we define the vectors $\bar{a}$ and $\bar{b}$ whose elements are respectively the coefficients of the numerator and denominator (Klein, 1976): 


$$
\begin{aligned}
& \stackrel{\bar{a}}{a}=\left(a_{0}, a_{1}, a_{2}, \ldots, a_{n}\right) \\
& \overline{=}=\left(b_{0}, b_{1}, b_{2}, \ldots, b_{n}\right)
\end{aligned}
$$

In order to express the numerator vectors $\bar{a}$ in terms of $\bar{A}$ and denominator vectors $\bar{b}$ in terms of $\bar{B}$, we replace the variable sin (1) by (4) then comparing the numerators and the denominators of the resulting transfer functions in $z$, we can identify the coefficients by equating the coefficients of the like powers in $z$.

Thus, for $n=2$ and $m=2$ we obtain the following expression:

$$
\begin{gathered}
H(z)=\frac{a_{0}+a_{1} z^{-1}+a_{2} z^{-2}}{b_{0}+b_{1} z^{-1}+b_{2} z^{-2}}= \\
=\frac{A_{0}+A_{1} c+A_{2} c^{2}+z^{-1}\left(2 A_{0}-2 A_{2} c^{2}\right)+}{B_{0}+B_{1} c+B_{2} c^{2}+z^{-1}\left(2 B_{0}-2 B_{2} c^{2)}+\right.} \\
\frac{+z^{-2}\left(A_{0}-A_{1} c+A_{2} c^{2}\right)}{+z^{-2}\left(B_{0}-B_{1} c+B_{2} c^{2}\right)}
\end{gathered}
$$

From the numerators the coefficients, $a_{i}$, $i=0,1,2$ are easily identified and re-written in acquire the following matrix equation

$$
\left[\begin{array}{l}
a_{0} \\
a_{1} \\
a_{2}
\end{array}\right]=\left[\begin{array}{ccc}
1 & 1 & 1 \\
2 & 0 & -2 \\
1 & -1 & 1
\end{array}\right] \times\left[\begin{array}{c}
A_{0} \\
A_{1} c \\
A_{2} c^{2}
\end{array}\right]
$$

In a similar manner, a matrix equation can be obtained for the coefficients, $b_{i}, i=0,1,2$ of the denominator vector $\bar{b}$.

Using a more compact representation both equations can be written as follows:

$$
\begin{aligned}
& \bar{a}=\bar{P}_{L P}^{(n)} \times \bar{A}^{\prime} \\
& \bar{b}=\bar{P}_{L P}^{(n)} \times \bar{B}^{\prime}
\end{aligned}
$$

where $\bar{P}_{L P}^{(n)}$ is the lowpass Pascal matrix defined in (P“eniñka et al., 2002) and the vectors $\overline{A^{\prime}}, \overline{B^{\prime}}$ are represented by

$$
\begin{aligned}
\overline{A^{\prime}} & =\left(A_{0}, A_{1} c, A_{2} c^{2}, \ldots, A_{m} c^{m}\right) \\
\overline{B^{\prime}} & =\left(B_{0}, B_{1} c, B_{2} c^{2}, \ldots, B_{m} c^{m}\right)
\end{aligned}
$$

As demonstrated in (P“eniñka et al., 2002) the computation of the $\bar{P}_{L P}^{(n)}$ matrix can be done in a systematic form. For this we consider the classical Pascal Triangle

$$
\begin{aligned}
& 1 \quad n=0 \\
& 1 \quad 1 \quad n=1 \\
& 121 \quad n=2 \\
& \begin{array}{rrrrrrrrrr} 
& 1 & & 3 & & 3 & & 1 & & n=3 \\
1 & & & & 6 & & 4 & 1 & n=4
\end{array} \\
& 1510 \quad 10 \quad 5 \quad 1 n=5
\end{aligned}
$$

Obs

erve, that the coefficients of base $n=2$ create the last column in the lowpass Pascal matrix of (8) with the exception of the elements in the even rows which have negative values. We have concluded that thelowpass Pascal matrix can be formed by taking into account the following rules (Biolkova and Biolek, 1999); (Pham and Psenicka, 1985).

- In the first row of the Pascal matrix all the elements must be equal to one.

- The elements of the last column can be computed using:

$$
P_{i, n+1}=(-1)^{i-1} \frac{n !}{(n-i+1) !(i-1) !}
$$

where

$$
i=1,2, \ldots, n+1
$$


The remaining elements $P_{i, j}$ of the lowpass Pascal matrix can be determined using the following equation:

$$
P_{i, j}=P_{i-1, j}+P_{i-1, j+1}+P_{i, j+1}
$$

where

$$
\begin{gathered}
i=2,3,4, \ldots, n, n+1 \\
j=n, n-1, n-2, \ldots, 2,1
\end{gathered}
$$

Without lost of generality, using letters of the alphabet in the order shown below we can identify the elements of thelowpass Pascal matrix for $n=4$ :

$$
\left[\begin{array}{ccccc}
a=1 & b=1 & c=1 & d=1 & e=1 \\
j & i & h & g & f=-4 \\
? & ? & ? & ? & k=6 \\
? & ? & ? & ? & l=-4 \\
? & ? & ? & ? & p=1
\end{array}\right]
$$

where the elements denoted $g, h, i$, and $j$ can be obtained using the next set of equations:

$$
\begin{array}{cc}
g=d+e+f=-2 ; & h=c+d+g=0 \\
i=b+c+h=2 ; & j=a+b+i=4
\end{array}
$$

Then the lowpass Pascal matrix for the particular case of $n=4$ is finally given by:

$$
\bar{P}_{L P}^{(4)}=\left[\begin{array}{ccccc}
1 & 1 & 1 & 1 & 1 \\
4 & 2 & 0 & -2 & -4 \\
6 & 0 & -2 & 0 & 6 \\
4 & -2 & 0 & 2 & -4 \\
1 & -1 & 1 & -1 & 1
\end{array}\right]
$$

\section{Lowpass-to-highpass Transformation}

In this second case, in order to transform the lowpass transfer function to the discrete highpass transfer function $H(z)$, we substitute the variable $s$ by $1 / s$ in (4). Thus,

$$
s=k \frac{z+1}{z-1}
$$

with

$$
k=\tan \frac{\pi f_{c}}{f_{s}}
$$

where $f_{c}$ represents the cut-off frequency of the highpass and $f_{s}$ the sampling frequency. Following the same process, substituting (17) into (1) and comparing the numerator with (3) for $n=3$ and $m=3$, we can obtain:

$$
\begin{gathered}
a_{0}+a_{1} z^{-1}+a_{2} z^{-2}+a_{3} z^{-3}= \\
A_{0}+A_{1} k+A_{2} k^{2}+A_{3} k^{3}+ \\
+z^{-1}\left(-3 A_{0}-A_{1} k+A_{2} k^{2}+3 A_{3} k^{3}\right)+ \\
+z^{-2}\left(3 A_{0}-A_{1} k-A_{2} k^{2}+3 A_{3} k^{3}\right)+ \\
+z^{-3}\left(-A_{0}+A_{1} k-A_{2} k^{2}+A_{3} k^{3}\right)
\end{gathered}
$$

Again, equating the coefficients of the like powers in $z$, we obtain the following matrix equation

$$
\left[\begin{array}{l}
a_{0} \\
a_{1} \\
a_{2}
\end{array}\right]=\left[\begin{array}{cccc}
1 & 1 & 1 & 1 \\
-3 & -1 & 1 & 3 \\
3 & -1 & -1 & 3 \\
-1 & 1 & -1 & 1
\end{array}\right] \times\left[\begin{array}{c}
A_{0} \\
A_{1} k \\
A_{2} k^{2} \\
A_{3} k^{3}
\end{array}\right]
$$

This equation can be written in the compact form

$$
\bar{a}=\bar{P}_{H P}^{(3)} \times \overline{A^{\prime \prime}}
$$

where $\bar{P}_{H P}^{(3)}$ is a variant of a Pascal matrix which corresponds to the highpass filter in which the first row elements are all equal to one, and the elements of the first column can 
be obtained using (12). The remaining elements $P_{i, j}$ can be determined using the following expression (P“eniñka et al., 2002):

$$
P_{i, j}=P_{i, j-1}+P_{i-1, j-1}+P_{i-1, j}
$$

Where

$$
\begin{aligned}
& i=2,3, \ldots, n+1 \\
& j=2,3, \ldots, n+1
\end{aligned}
$$

A similar development can be done for the denominator vector $\bar{b}$.

\section{Lowpass-to-bandpass Transformation}

The latest case considered in this paper shows how to obtain a discrete bandpass filter (Konopacki, 2005) characterized by the discrete-time transfer function $\mathrm{H}(\mathrm{z})$

$$
H(z)=\frac{a_{0}+a_{1} z^{-1}+a_{2} z^{-2}+\ldots+a_{n} z^{-n}}{b_{0}+b_{1} z^{-1}+b_{2} z^{-2}+\ldots+b_{n} z^{-n}}
$$

which also has real coefficients $a_{i}$ and $b_{i}$. As previously this transfer function can be obtained from the continuous one (1) by $s-z$ transformation. The bandpass filter can be seen as a superposition of a lowpass filter and a highpass filter (Rabiner and Gold, 1975). Thus, the $s-z$ transformation that applies is (Bose, 1985):

$$
s=c \frac{z-1}{z+1}+k \frac{z+1}{z-1}
$$

where $\quad c=\cot \left(\pi \frac{f_{1}}{f_{s}}\right) \quad k=\tan \left(\pi \frac{f_{-1}}{f_{s}}\right)$

$f_{1}$ and $f_{-1}$ represent the upper and lower frequencies of the bandpass filter respectively, and $f_{s}$ the sampling frequency.

In a similar manner from (22), we define the coefficient vectors $\bar{a}$ and $\bar{b}$ :

$$
\begin{gathered}
\bar{a}\left(a_{0}, a_{1}, a_{2}, \ldots, a_{n}\right) \\
\bar{b}\left(b_{0}, b_{1}, b_{2}, \ldots, b_{n}\right)
\end{gathered}
$$

In order to obtain the coefficients $a_{i}$ and $b_{i}$ $(i=0,1, \ldots, n)$ knowing the continuous time representation vectors $\bar{A}$ and $\bar{B}$, we must first substitute (23) into (1) then compare the numerator and denominator of the resulting transfer function with the corresponding ones in (22).

For example without lost of generalization we take $m=1$ in (1), due to the high order terms appearing in the transformation (23), a $n=2$ must taken in (22) resulting in:

$$
\begin{gathered}
H(z)=\frac{A(z)}{B(z)}=\frac{a_{0}+a_{1} z^{-1}+a_{2} z^{-2}}{b_{0}+b_{1} z^{-1}+b_{2} z^{-2}}= \\
\frac{A_{0}+A_{1} c+A_{1} k+z^{-1}\left(2 A_{1} k-2 A_{1} c\right)+}{B_{0}+B_{1} c+B_{1} k+z^{-1}\left(2 B_{1} k-2 B_{1} c\right)+} \\
\frac{+z^{-2}\left(-A_{0}+A_{1} c+A_{1} k\right)}{+z^{-2}\left(-B_{0}+B_{1} c+B_{1} k\right)}
\end{gathered}
$$

and the following matrix equation:

$$
\left[\begin{array}{l}
a_{0} \\
a_{1} \\
a_{2}
\end{array}\left[\begin{array}{ccc}
1 & 1 & 1 \\
-2 & 0 & 2 \\
1 & -1 & 1
\end{array}\right] \times\left[\begin{array}{l}
A_{1} c \\
A_{0} \\
A_{1} k
\end{array}\right]\right.
$$

A similar equation is obtained for the denominator vector $\bar{b}$. Both equations can be represented in the following compact form:

$$
\begin{aligned}
& \bar{a}=\bar{P}_{B P}^{n} \times \overline{A^{\prime \prime \prime}} \\
& \bar{b}=\bar{P}_{B P}^{n} \times \overline{B^{\prime \prime \prime}}
\end{aligned}
$$

where $\bar{P}_{B P}^{n}$ is the so called bandpass Pascal matrix. This matrix transforms the normalized lowpass to bandpass transfer function. We have named this matrix the bandpass 
Pascal matrix (Psenicka and García-Ugalde, 2004) because the matrices of all orders have in the first column the coefficients of the base of a Pascal triangle (11) with the exception of elements in even rows, which have negative signs. In this example the vectors $A^{\prime \prime}$ and $B^{\prime \prime}$ are represented respectively by

$$
\begin{aligned}
& \overline{A^{\prime \prime \prime}}=\left(A_{1} c, A_{0}, A_{1} k\right) \\
& \overline{B^{\prime \prime \prime}}=\left(B_{1} c, B_{0}, B_{1} k\right)
\end{aligned}
$$

In order to achieve an alternative representation of the original bandpass Pascal matrix, without lost of generality let us consider the case of order $m=2$ and again because of the high order terms appearing in the transformation (23), a $n=4$ must taken. The matrix representation of $\bar{a}=\bar{P}_{P P}^{n} \times \bar{A}^{\prime \prime \prime}$ is given by

$$
\left[\begin{array}{l}
a_{0} \\
a_{1} \\
a_{2} \\
a_{3} \\
a_{4}
\end{array}\right]=\left[\begin{array}{cccccc}
1 & 1 & 1 & 1 & 1 & 1 \\
-4 & -2 & 0 & 2 & 4 & 0 \\
6 & 0 & -2 & 0 & 6 & -2 \\
-4 & 2 & 0 & -2 & 4 & 0 \\
1 & -1 & 1 & -1 & 1 & 1
\end{array}\right] \times\left[\begin{array}{l}
A_{2} c^{2} \\
A_{1} c \\
A_{0} \\
A_{1} k \\
A_{2} k^{2} \\
2 A_{2} c k
\end{array}\right]
$$

Note from this latest example that the matrix is rectangular and it will be the general case in a lowpass-to-bandpass transformation for values of $m=2$ or higher. In order to use the same rules as in the previous section for the lowpass-to-highpass transformation (which always has a square matrix) we decompose this rectangular matrix into the concatenation of two matrices as shown in the following equation

$$
\left[\bar{P}_{B P}^{n}\right]=\left[\bar{S}_{B P}^{n} \mid \bar{R}_{B P}^{n}\right]
$$

In this equation the matrix $\bar{S}_{B P}^{n}$ is square and its computation is exactly the same as that used in the lowpass-to-highpass transformation, which means: all the terms in the first column can be obtained using (12) and the remaining elements $S_{i j}$ can be established using the following expression (P"eni Nka et al., 2002):

$$
S_{i j}=S_{i, j-1}+S_{i-1, j-1}+S_{i-1, j}
$$

Where

$$
\begin{aligned}
& i=2,3, \ldots, n+1 \\
& j=2,3, \ldots, n+1
\end{aligned}
$$

On the other hand the matrix $\bar{R}_{B P}^{n}$ in (30) is rectangular with $n+1$ rows. A priori the number of columns has to be computed by counting the number of elements different to 1 included in the upper triangle from base $m$ of the Pascal triangle (11). To illustrate these values we summarize in table 1 the number of columns col of matrix $\bar{R}_{B P}^{n}$ for different $m$ and $n$ parameter values.

Table 1. Number of columns col in the matrix $\bar{R}_{B P}^{n}$

\begin{tabular}{ccc}
\hline$m$ & $n$ & col \\
\hline 2 & 4 & 1 \\
3 & 6 & 3 \\
4 & 8 & 6 \\
\hline
\end{tabular}

Once the elements of matrix $\bar{S}_{B P}^{n}$ are known the columns of $\bar{R}_{B P}^{n}$ can be derived directly. Let us consider the case $m=2$, the lonely column of $\bar{R}_{B P}^{n}$ is equal to the central column of $\bar{S}_{B P}^{n}$ (P“ eninkka and García-Ugalde, 2004). In this paper we call this column the pivot because for $m=2$ there is only one element different to 1 in the upper triangle from base $m$ in the Pascal triangle and its position corresponds to a central position in the triangle. For $m=3$, as shown in table 1, 
there are three columns in $\bar{R}^{n} B$, one is also the pivot because again it is equal to the central column of $\bar{S}_{B P}^{n}$ and the two others are the columns on the right of the pivot and on the left of it. Also the reason is because for $m=3$ there are three elements different to one in the upper trian- gle from base $m$ and their positions corres- pond to a central position in the triangle plus its nearest neighbors (right and left). To illustrate the previous structure we show the resulting $\bar{P}_{B P}^{n}$ matrix for vector $\bar{a}$ and pa- rameters $m=3, n=6$.

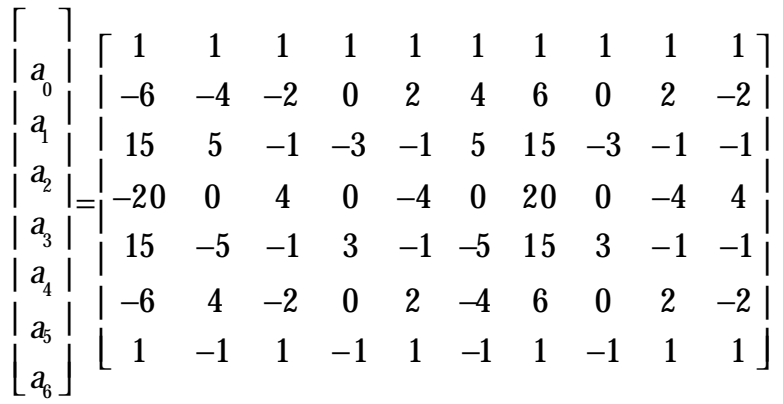

$$
\begin{aligned}
& \times\left[\begin{array}{l}
A_{3} c^{3} \\
A_{2} C^{2} \\
A_{1} c \\
A_{0} \\
A_{1} k \\
A_{2} k^{2} \\
A_{3} k^{3} \\
2 A_{2} c k \\
3 A_{3} c k^{2} \\
3 A_{3} c^{2} k
\end{array}\right]
\end{aligned}
$$

A similar expression can be obtained for vector $\bar{b}$.

\section{Inverse Transformation from $\mathrm{H}(\mathrm{z})$ to $\mathrm{H}(\mathrm{s})$}

The inverse Pascal matrix is defined by the following equation (Klein, 1976):

$$
\bar{P}^{-1}=2^{-n} \times \bar{P}^{n}
$$

In all cases using the inverse Pascal matrix the continuous-time transfer function $\mathrm{H}(\mathrm{s})$ can be obtained from the transfer matrix of the discrete-time structure $H(z)$. The advantage of using this equation is that to compute the inverse Pascal matrix the determinant of the system is not necessary.

For example consider the lowpass case, let $H(z)$ be the transfer function of the discrete structure that works at the corner frequency $f_{1}=3400[\mathrm{~Hz}]$ and sampling frequency $f_{s}=16000[\mathrm{~Hz}]$.

$$
H(z)=\frac{0.227+0.454 z^{-1}+0227 z^{-2}}{1-0.276 z^{-1}+0.185 z^{-2}}
$$

First it is necessary to calculate the constant $c$ of the bilinear transform (1):

$$
c=\cot \left(\frac{\pi 3400}{16000}\right)=126849
$$

Then the transfer function coefficients of the analog circuit will be calculated as follows:

$$
\begin{aligned}
& {\left[\begin{array}{l}
A_{0} \\
A_{1} c \\
A_{2} c^{2}
\end{array}\right]=\frac{1}{4}\left[\begin{array}{ccc}
1 & 1 & 1 \\
2 & 0 & -2 \\
1 & -1 & 1
\end{array}\right]\left[\begin{array}{l}
0.227 \\
0.454 \\
0.227
\end{array}\right]=\left[\begin{array}{l}
0.227 \\
0.0 \\
0.0
\end{array}\right]} \\
& {\left[\begin{array}{l}
B_{0} \\
B_{1} c \\
B_{2} c^{2}
\end{array}\right]=\frac{1}{4}\left[\begin{array}{ccc}
1 & 1 & 1 \\
2 & 0 & -2 \\
1 & -1 & 1
\end{array}\right]\left[\begin{array}{l}
1 \\
-0.276 \\
0.185
\end{array}\right]=\left[\begin{array}{l}
0227 \\
0.407 \\
0.365
\end{array}\right]}
\end{aligned}
$$

and

$$
\begin{array}{ccc}
A_{0}=0227 & A_{1}=0.0 & A_{2}=0.0 \\
B_{0}=0.227 & B_{1}=0.321 & B_{2}=0227
\end{array}
$$




\section{Prac tical Design of Digital Filters Using the Pascal Matrix}

The transfer function of the corresponding analog filter is the Butterworth transfer function of the second order:

$$
\begin{gathered}
H(s)=\frac{0.227}{0.227 s^{2}+0.321 s+0.227}= \\
=\frac{1}{s^{2}+1.4142 s+1}
\end{gathered}
$$

\section{Numerical Exam ples}

In these examples we shall transform a lowpass transfer function $H(s)$ to lowpass and highpass transfer functions $H(z)$ using the features specified by:

$$
\begin{gathered}
c=k=1, \quad f_{s}=8000[\mathrm{~Hz}] \\
H(s)=\frac{s^{2}+5.153}{0.929 s^{3}+2.781 s^{2}+4.344 s+5.153}
\end{gathered}
$$

Trans for ma tion LP-to-LP from s to the $z$ domain

The transfer function coefficients $a_{i}, b_{i}$, for $i=0,1,2,3$ can then be obtained using the equations:

$$
\begin{gathered}
{\left[\begin{array}{l}
a_{0} \\
a_{1} \\
a_{2} \\
a_{3}
\end{array}\right]=\left[\begin{array}{cccc}
1 & 1 & 1 & 1 \\
3 & 1 & -1 & -3 \\
3 & -1 & -1 & 3 \\
1 & -1 & 1 & -1
\end{array}\right] \times\left[\begin{array}{l}
A_{0} \\
A_{1} c \\
A_{2} c^{2} \\
A_{3} c^{3}
\end{array}\right]=} \\
=\left[\begin{array}{cccc}
1 & 1 & 1 & 1 \\
3 & 1 & -1 & -3 \\
3 & -1 & -1 & 3 \\
1 & -1 & 1 & -1
\end{array}\right] \times\left[\begin{array}{l}
5153 \\
0.0 \\
1.0 \\
0.0
\end{array}\right]
\end{gathered}
$$

$$
\left[\begin{array}{l}
b_{0} \\
b_{1} \\
b_{2} \\
b_{3}
\end{array}\right]=\left[\begin{array}{cccc}
1 & 1 & 1 & 1 \\
3 & 1 & -1 & -3 \\
3 & -1 & -1 & 3 \\
1 & -1 & 1 & -1
\end{array}\right] \times\left[\begin{array}{l}
B_{0} \\
B_{1} c \\
B_{2} c^{2} \\
B_{3} c^{3}
\end{array}\right]=
$$

$$
=\left[\begin{array}{cccc}
1 & 1 & 1 & 1 \\
3 & 1 & -1 & -3 \\
3 & -1 & -1 & 3 \\
1 & -1 & 1 & -1
\end{array}\right] \times\left[\begin{array}{c}
5153 \\
4.344 \\
2.781 \\
0.929
\end{array}\right]
$$

given

$$
\begin{aligned}
& a_{0}=6153, a_{1}=14.459, a_{2}=14.459, a_{3}=6.153 \\
& b_{0}=13.207, b_{1}=14.235, b_{2}=11.121, b_{3}=2.661
\end{aligned}
$$

The transfer function $H(z)$ takes the form

$$
\begin{gathered}
H(z)= \\
=\frac{0.4658+1.0948 z^{-1}+1.0948 z^{-2}+0.4658 z^{-3}}{1+1.0778 z^{-1}+0.842 z^{-2}+0.2015 z^{-3}}
\end{gathered}
$$

For this equation the corresponding magnitude and phase frequency responses of the digital lowpass filter are shown in Figure 1. 

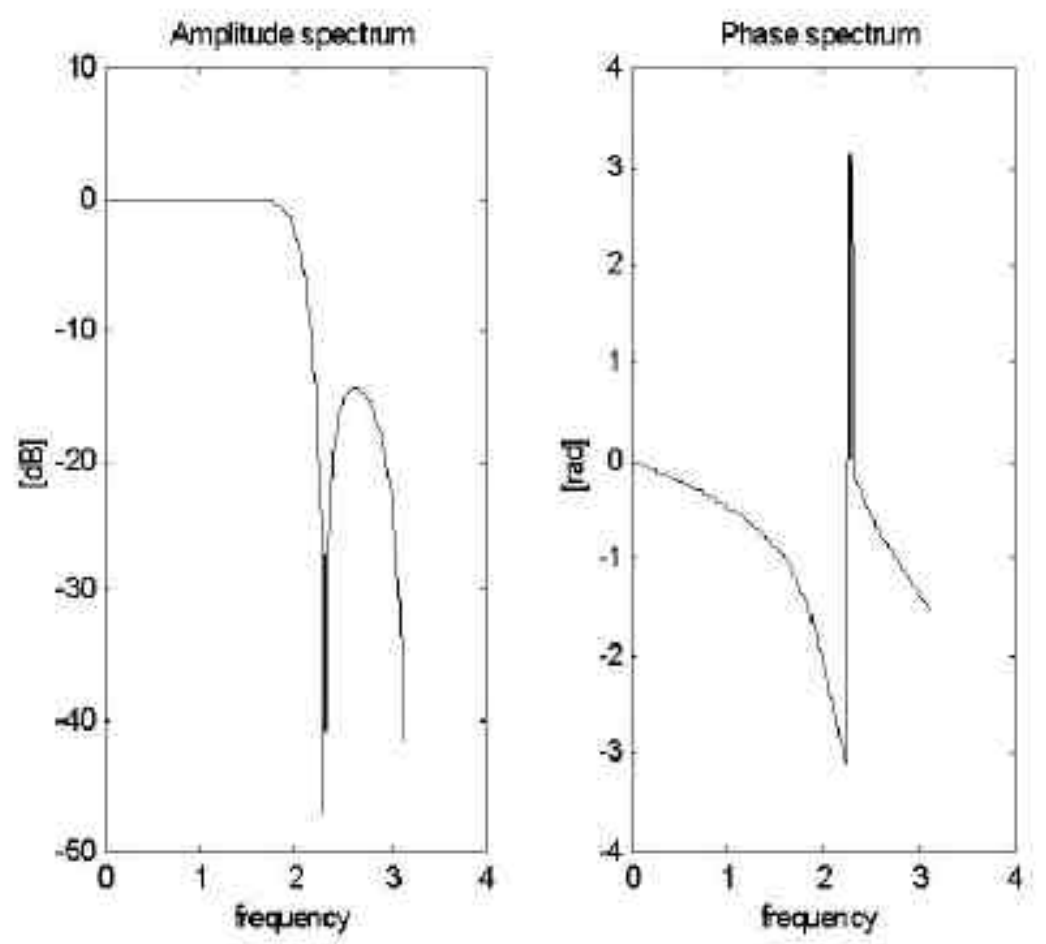

Figure 1. Magni tude and phase frequency responses of the lowpass filter

Transformation LP-to-HP from s to the $z$ domain

Using the Pascal matrix $\bar{P}_{H P}^{(3)}$ we can transform the lowpass transfer function (38) to the highpass transfer function $H(z)$ using the following equations:

$$
\left[\begin{array}{l}
a_{0} \\
a_{1} \\
a_{2} \\
a_{3}
\end{array}\right]=\left[\begin{array}{cccc}
1 & 1 & 1 & 1 \\
-3 & -1 & 1 & 3 \\
3 & -1 & -1 & 3 \\
-1 & 1 & -1 & 1
\end{array}\right] \times\left[\begin{array}{l}
A_{0} \\
A_{1} k \\
A_{2} k^{2} \\
A_{3} k^{3}
\end{array}\right]=
$$

$$
=\left[\begin{array}{cccc}
1 & 1 & 1 & 1 \\
-3 & -1 & 1 & 3 \\
3 & -1 & -1 & 3 \\
-1 & 1 & -1 & 1
\end{array}\right] \times\left[\begin{array}{l}
5153 \\
0.0 \\
1.0 \\
0.0
\end{array}\right]
$$

$$
\left[\begin{array}{l}
b_{0} \\
b_{1} \\
b_{2} \\
b_{3}
\end{array}\right]=\left[\begin{array}{cccc}
1 & 1 & 1 & 1 \\
-3 & -1 & 1 & 3 \\
3 & -1 & -1 & 3 \\
-1 & 1 & -1 & 1
\end{array}\right] \times\left[\begin{array}{l}
B_{0} \\
B_{1} k \\
B_{2} k^{2} \\
B_{3} k^{3}
\end{array}\right]
$$

$$
=\left[\begin{array}{cccc}
1 & 1 & 1 & 1 \\
-3 & -1 & 1 & 3 \\
3 & -1 & -1 & 3 \\
-1 & 1 & -1 & 1
\end{array}\right] \times\left[\begin{array}{c}
5.153 \\
4.344 \\
2.781 \\
0.929
\end{array}\right]
$$

The coefficients of the highpass transfer function are:

$$
\begin{aligned}
& a_{0}=6153, \quad a_{1}=-14.459 \\
& a_{2}=14.459, \quad a_{3}=6153 \\
& b_{0}=13.207, \quad b_{1}=-14.235
\end{aligned}
$$




$$
b_{2}=11.121, \quad b_{3}=-2.661
$$

and the highpass transfer function is given by (44). The magnitude and phase frequency responses of the digital highpass filter are shown in Figure 2.

$$
\begin{gathered}
H(z)= \\
=\frac{0.4658-1.0948 z^{-1}+1.0948 z^{-2}-0.4658 z^{-3}}{1-1.0778 z^{-1}+0.842 z^{-2}-0.2015 z^{-3}}
\end{gathered}
$$

Trans for ma tion LP-to-BP from s to the $z$ domain

In this example we transform a Butterworth lowpass transfer function $H(s)$ to a bandpass transfer function $H(z)$ using the features specified by:

$$
\begin{aligned}
& f_{1}=300[\mathrm{~Hz}], f_{-1}=1000[\mathrm{~Hz}] \\
& f_{s}=800[\mathrm{~Hz}] \\
& H(s)=\frac{1}{s^{2}+\sqrt{2 s+1}}
\end{aligned}
$$

In order to transform the lowpass analog function (45) into the digital bandpass function, we must first determine the transfer function coefficients $a_{1}, b_{1}$ for $i=0,1, \ldots, 4$ which can be obtained using the matrix equations for current values:

$$
\begin{aligned}
& c=\cot \left(\frac{\pi 3000}{8000}\right)=0.4142 \\
& k=\tan \left(\frac{\pi 1000}{8000}\right)=0.4142
\end{aligned}
$$
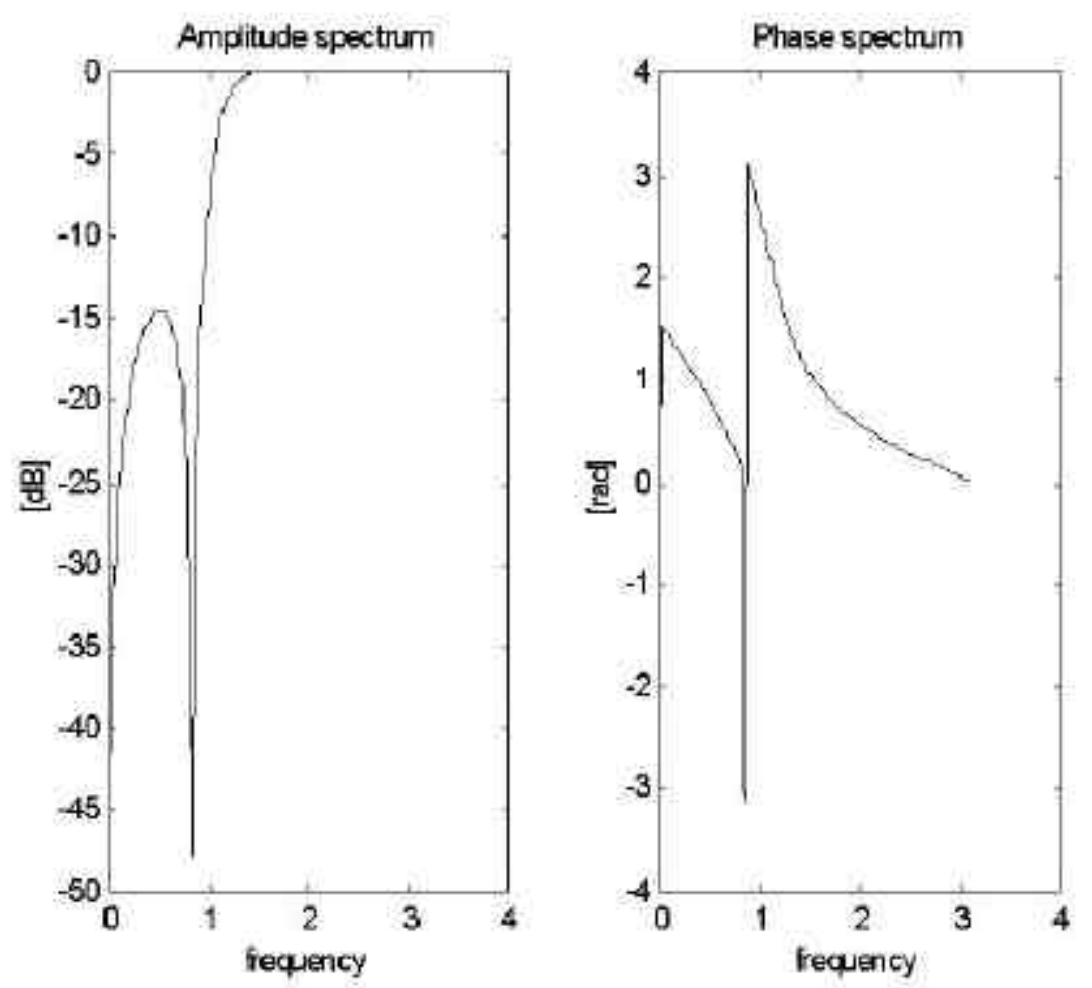

Figure 2. Magni tude and phase frequency responses of the highpass filter 


$$
\left[\begin{array}{l}
a_{0} \\
a_{1} \\
a_{2} \\
a_{3} \\
a_{4}
\end{array}\right]=\left[\begin{array}{cccccc}
1 & 1 & 1 & 1 & 1 & 1 \\
-4 & -2 & 0 & 2 & 4 & 0 \\
6 & 0 & -2 & 0 & 6 & -2 \\
-4 & 2 & 0 & -2 & 4 & 0 \\
1 & -1 & 1 & -1 & 1 & 1
\end{array}\right] \times\left[\begin{array}{l}
A_{2} c^{2} \\
A_{1} c \\
A_{0} \\
A_{1} k \\
A_{2} k^{2} \\
2 A_{2} c k
\end{array}\right]=
$$

$$
=\left[\begin{array}{cccccc}
1 & 1 & 1 & 1 & 1 & 1 \\
-4 & -2 & 0 & 2 & 4 & 0 \\
6 & 0 & -2 & 0 & 6 & -2 \\
-4 & 2 & 0 & -2 & 4 & 0 \\
1 & -1 & 1 & -1 & 1 & 1
\end{array}\right] \times\left[\begin{array}{l}
0 \\
0 \\
1 \\
0 \\
0 \\
0
\end{array}\right]=\left[\begin{array}{l}
1 \\
0 \\
-2 \\
0 \\
1
\end{array}\right]
$$

$$
\left[\begin{array}{l}
b_{0} \\
b_{1} \\
b_{2} \\
b_{3} \\
b_{4}
\end{array}\right]=\left[\begin{array}{cccccc}
1 & 1 & 1 & 1 & 1 & 1 \\
-4 & -2 & 0 & 2 & 4 & 0 \\
6 & 0 & -2 & 0 & 6 & -2 \\
-4 & 2 & 0 & -2 & 4 & 0 \\
1 & -1 & 1 & -1 & 1 & 1
\end{array}\right] \times\left[\begin{array}{l}
B_{2} c^{2} \\
B_{1} c \\
B_{0} \\
B_{1} k \\
B_{2} k^{2} \\
2 B_{2} c k
\end{array}\right]=
$$

$$
=\left[\begin{array}{cccccc}
1 & 1 & 1 & 1 & 1 & 1 \\
-4 & -2 & 0 & 2 & 4 & 0 \\
6 & 0 & -2 & 0 & 6 & -2 \\
-4 & 2 & 0 & -2 & 4 & 0 \\
1 & -1 & 1 & -1 & 1 & 1
\end{array}\right] \times\left[\begin{array}{l}
0.1716 \\
0.5858 \\
1 \\
0.5858 \\
0.1716 \\
0.3431
\end{array}\right]=\left[\begin{array}{l}
2.8579 \\
0 \\
-0.627 \\
0 \\
0.5147
\end{array}\right]
$$

The transfer function of the bandpass filter is given by

$$
\begin{gathered}
H(z)= \\
=\frac{0.3499-0.6998 z^{-2}+0.3499 z^{-4}}{1-02194 z^{-2}+01801 z^{-4}}
\end{gathered}
$$

Finally, a more complicated example is presented, in which the lowpass transfer function $H(s)$ contains two transfer functions $H_{1}(s)$ and $H_{2}(s)$ and is transformed into the whole system bandpass transfer function $H(z)$ for $f_{1}=3000[\mathrm{~Hz}], f_{-1}=1000[\mathrm{~Hz}], f_{s}=8000[\mathrm{~Hz}]$

$$
\begin{gathered}
H(s)=H_{1}(s) \times H_{2}(s)= \\
\frac{0123}{s+0.3497} \times \frac{s^{2}+0.2897}{s^{2}+0.0492 s+02492}
\end{gathered}
$$

In order to transform the lowpass analog function (49) into the digital bandpass function, we proceed the $s-z$ transformation for each of these two transfer functions, we must first establish the coefficients $a_{i}, b_{i}$, for $i=0,1,2$ for the first function $H_{1}(z)$ and then the coefficients $a_{i}, b_{i}$, for $i=0,1,2, \ldots, 4$ for the second one $H_{2}(z)$. This computation can be obtained using the matrix equations previously defined for current values:

$$
\begin{aligned}
& c=\cot \left(\frac{\pi 3000}{8000}\right)=0.4142 \\
& k=\tan \left(\frac{\pi 1000}{8000}\right)=0.4142
\end{aligned}
$$

$$
\begin{array}{r}
{\left[\begin{array}{l}
a_{0} \\
a_{1} \\
a_{2}
\end{array}\right]=\left[\begin{array}{ccc}
1 & 1 & 1 \\
-2 & 0 & 2 \\
1 & -1 & 1
\end{array}\right] \times\left[\begin{array}{l}
A_{1} c \\
A_{0} \\
A_{1} k
\end{array}\right]=} \\
=\left[\begin{array}{ccc}
1 & 1 & 1 \\
-2 & 0 & 2 \\
1 & -1 & 1
\end{array}\right] \times\left[\begin{array}{l}
0 \\
0.123 \\
0
\end{array}\right]=\left[\begin{array}{l}
0.123 \\
0 \\
-0.123
\end{array}\right]
\end{array}
$$




$$
\begin{aligned}
& {\left[\begin{array}{l}
b_{0} \\
b_{1} \\
b_{2}
\end{array}\right]=\left[\begin{array}{ccc}
1 & 1 & 1 \\
-2 & 0 & 2 \\
1 & -1 & 1
\end{array}\right] \times\left[\begin{array}{l}
B_{1} c \\
B_{0} \\
B_{1} k
\end{array}\right]=} \\
& =\left[\begin{array}{ccc}
1 & 1 & 1 \\
-2 & 0 & 2 \\
1 & -1 & 1
\end{array}\right] \times\left[\begin{array}{l}
0.4142 \\
0.3497 \\
0.4142
\end{array}\right]=\left[\begin{array}{l}
1.1781 \\
0 \\
0.4787
\end{array}\right]
\end{aligned}
$$

$$
\left[\begin{array}{l}
a_{0} \\
a_{1} \\
a_{2} \\
a_{3} \\
a_{4}
\end{array}\right]=\left[\begin{array}{cccccc}
1 & 1 & 1 & 1 & 1 & 1 \\
-4 & -2 & 0 & 2 & 4 & 0 \\
6 & 0 & -2 & 0 & 6 & -2 \\
-4 & 2 & 0 & -2 & 4 & 0 \\
1 & -1 & 1 & -1 & 1 & 1
\end{array}\right] \times\left[\begin{array}{l}
A_{2} c^{2} \\
A_{1} c \\
A_{0} \\
A_{1} k \\
A_{2} k^{2} \\
2 A_{2} c k
\end{array}\right]=
$$$$
=\left[\begin{array}{cccccc}
1 & 1 & 1 & 1 & 1 & 1 \\
-4 & -2 & 0 & 2 & 4 & 0 \\
6 & 0 & -2 & 0 & 6 & -2 \\
-4 & 2 & 0 & -2 & 4 & 0 \\
1 & -1 & 1 & -1 & 1 & 1
\end{array}\right] \times\left[\begin{array}{l}
0.1716 \\
0 \\
02897 \\
0 \\
0.1716 \\
03431
\end{array}\right]=
$$$$
=\left[\begin{array}{l}
0.976 \\
0 \\
0.7936 \\
0 \\
0.976
\end{array}\right]
$$

$$
=\left[\begin{array}{cccccc}
1 & 1 & 1 & 1 & 1 & 1 \\
-4 & -2 & 0 & 2 & 4 & 0 \\
6 & 0 & -2 & 0 & 6 & -2 \\
-4 & 2 & 0 & -2 & 4 & 0 \\
1 & -1 & 1 & -1 & 1 & 1
\end{array}\right] \times\left[\begin{array}{l}
0.1716 \\
0.0204 \\
0.2492 \\
0.0204 \\
0.1716 \\
0.3431
\end{array}\right]=
$$

$$
=\left[\begin{array}{l}
0.9763 \\
0 \\
0.8746 \\
0 \\
0.8946
\end{array}\right]
$$

The whole system transfer function in $z$ of the bandpass filter is given in (54) and the corresponding magnitude and phase frequency responses are shown in Figure 3.

$$
\begin{gathered}
H(z)=H_{1}(z) \times H_{2}(z)= \\
=\frac{0.123-0.123 z^{-2}}{11781+0.4787 z^{-2}} \times \\
\times \frac{0.976+0.7936 z^{-2}+0.976 z^{-4}}{0.9763+0.8746 z^{-2}+0.8946 z^{-4}}
\end{gathered}
$$

$$
\left[\begin{array}{l}
b_{0} \\
b_{1} \\
b_{2} \\
b_{3} \\
b_{4}
\end{array}\right]=\left[\begin{array}{cccccc}
1 & 1 & 1 & 1 & 1 & 1 \\
-4 & -2 & 0 & 2 & 4 & 0 \\
6 & 0 & -2 & 0 & 6 & -2 \\
-4 & 2 & 0 & -2 & 4 & 0 \\
1 & -1 & 1 & -1 & 1 & 1
\end{array}\right] \times\left[\begin{array}{l}
B_{2} c^{2} \\
B_{1} c \\
B_{0} \\
B_{1} k \\
B_{2} k^{2} \\
2 B_{2} c k
\end{array}\right]=
$$




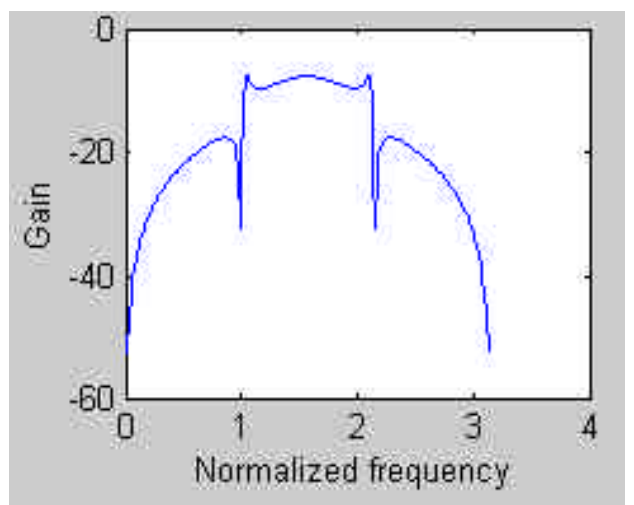

Figure 3. Magni tude and phase frequency responses of the Cauer bandpass filter.

\section{Conclusions}

The Pascal matrix is very useful in the context of the design of digital filters. Transformations can easily be done from the analog prototype lowpass transfer function $H(s)$ to the discrete transfer function $H(z)$ to obtain one of the main three types of digital filters: lowpass, highpass and bandpass. The inverse transformation from discrete to analog is very easy to achieve as well because we do not need to compute the determinant of the system. In this paper we have summarized all types of direct transformations and illustrate their use with several numerical examples. An alternative representation of the original bandpass Pascal matrix has been presented for the systematic computation of the bandpass Pascal matrix.

\section{Acknowledgements}

This research was supported by CONACyT México, project 41069-Y and DGAPA-UNAM, project IN101305.

\section{References}

Antoniou A. (1993). Digital Filters: Analysis, Design, and Applications. McGrawHill, New York, USA.
Biolkova V. and Biolek D. (1999). Generalized Pascal Matrix of First Order $s-z$. Trans forms. ICECS, Pafos, Cyprus, Vol. 2, pp. 929-931, September.

Bose N.K. (1985). Digital Filters Theory and Applications. Elsevier Science $\mathrm{Pu}$ blishing Co., Inc., Amsterdam, The Netherlands.

Klein W. (1976). Finite Systemtheorie. B.G. Teubner Studienbücher, Stuttgart.

Konopacki J. (2005). The frequency Transformation by Matrix Opera tion ans its Application in iir Filters Design. IEEE Signal Processing Letters, Vol. 12, No. 1, pp. 5-8, January.

Parks T.W. and Burrus C. (1987). Digital Filter Design. John Willey and Sons, Inc., New York, USA.

Pham Khac di and P“eni Ñka B. (1985). Transfer Function Computation Using Pascal Matrix. Electronic HorizonPraha, Vol 46-7, pp. 348-350.

P“eniñka B. and García-Ugalde F. (2004). Z-transform from Lowpass to Bandpass by Pascal Matrix. IEEE Signal Processing Letters, Vol. 11, No. 2, pp. 282-284, February.

P“eni ñka B., García-Ugalde F. and Herrera-Camacho A. (2002). Z-transfromation from Lowpass to Lowpass and Highpass Transfer Function. IEEE Signal 
Processing Letters, Vol. 9, No. 11, pp. 368-370, November.

Rabiner R. and Gold B. (1975). Theory and

Applications of Digital Signal Processing.

Prentice-Hall, New Jersey, USA.

\section{Suggesting Biography}

Bellanger M. (2000). Digital Processing of Signals, Theory and Practice. John Willey and Sons, Inc., Chichester, UK. Manolakis D.G. and Proakis J.G. (1996). Digital Signal Processing: Principles,
Algorithms, and Applications. PrenticeHall, New Jersey, USA.

Mitra S.K. and Kaiser J.F. (1993). Handbook of Digital Signal Processing. John Willey and Sons, Inc., New York, USA.

Oppenheim A.V. and Schafer R.W. (1975). Digital Signal Processing. Prentice-Hall, New Jersey, USA.

Porat B. (2000). A Course in Digital Signal Processing. John Willey and Sons, Inc., New York, USA.

Rorabaugh C.B. (1993). Digital Filter Designer's Handbook. McGraw-Hill, New York, USA.

\section{Semblanza de los autores}

Bohumil Pšenicka. Was born in Prague on April 15, 1933. He received the B.S. degree from Czech Tech nical Univer sity, Prague, in 1962, and the M.S. and Ph.D. degrees from Czech Tech nical Univer sity, Prague, in 1967 and 1972 respec tively. In 1993 he joined the Universidad Nacional Autónoma de México, Facultad de Ingeniería, where he is currently a full-time professor in the Depart ment of Tele com mu ni ca tion Engi neering. His research inter ests are Digital Signal Processing, Analog and Digital Filter Theory, and Applications of Microprocessors in Telecommunications.

Fran cisco García-Ugalde. Obtained his Bach elor in 1977 in Commu ni ca tions, Elec tronics and Control Engi neering from Universidad Nacional Autónoma de México. His Diplôme d'Ingénieur in 1980 from SUPELEC France, and his PhD in 1982 in Infor ma tion Processing from Université de Rennes I, France. Since 1983 is a full-time professor at UNAM (Universidad Nacional Autónoma de México), Facultad de Ingeniería. He's spent a sabbatical year at IRISA, France, in 1990, a second sabbat ical in 1996 at the HITLab in Univer sity of Wash ington, USA, and a third sabbat ical in 2003 in the depart ment of Cyber netics in Reading Univer sity, UK. Hiscurrent interest fields are: Digital filter design tools, Anal ysis and design of digital filters, Image and video c oding, Image anat ysis, Theory and appli ca tions of error control coding, Joint source-channel coding, Turbo coding, Applica tions of cryp tog raphy, Computer archi tec tures and Parallel processing.

Virginie F. Ruiz. MIEEE, MIEE, received her BSc, MSc and PhD in signal processing from the Univer sity of Rouen, France. She has the honour of being a recip ient of the French Foreign Office, Lavoisier programme. Her research focuses on the theory and applica tion of nonlinear filtering for esti ma tion, detec tion, predic tion, anal ysis, recog ni tion. She is concerned with the devel op ment of funda mental prin ci ples of finding new ways of describing and processing signals to tackle the more general and chal lenging non-linear, non-Gaussian, non-stationary prob lems. She has a long track record in the application of signal processing methods to medical signal and image processing, bioen gi neering, commu ni ca tions, synthetic aper ture radar, and mobile robotics. She has been with the Depart ment of Cyber netics at Univer sity of Reading since 1998. She is a senior lecturer in signal processing and chair of the Instru men ta tion and Signal Processing research group. Deputy Head of Cyber netics she is the Programme Director for several under grad uate programmes and is currently involved in a number of inter na tional research projects and indus trial projects. She is a member of many technical programme commit tees for inter na tional confer ences and serves as reviewer for a number of Inter national Jour nals. 